\title{
De Arce. A. (2016). Mujeres, familia y trabajo. Chacra, caña y algodón en la Argentina (1930-1960). Bernal, Argentina: Universidad Nacional de Quilmes.
}

Adrián Almirón ${ }^{1}$

La obra de la Alejandra De Arce Alejandra plantea una investigación novedosa e importante para los estudios agrarios, donde describe y reconstruye el rol de la mujer en el campo argentino, haciendo foco en la regiones Pampeana, Noroeste y Nordeste. El marco temporal abarca entre 1930 y 1960 , periodo muy estudiado en la historiografía rural, pero que presenta notables ausencias en torno al estudio sobre la trabajadora rural, más aún en el Norte Grande Argentino.

Para realizar esta investigación, la autora hizo uso de un variado corpus documental, desde publicaciones oficiales hasta revistas de la época especializadas en materia agraria ( $L a$ Chacra, Mundo Argentino, entre otras), a través del cual reconstruye las representaciones sobre la mujer de campo, abocada al espacio doméstico, al cuidado de la familia y trabajando, tanto para la autosubsistencia como en los cultivos industriales, destacándose en la zafra y en la cosecha de algodón.

El Estado nacional durante este periodo tuvo el objetivo de afianzar los asentamientos rurales y fortalecer las unidades productivas. Desde una matriz de pensamiento patriarcal, la mujer estaba restringida al espacio domésti- co, considerada como la «dueña del hogar». La política estatal estuvo orientada a fortalecer este lugar de la mujer, con el objetivo de consolidar un modelo familiar y normativizar a las mujeres para evitar el éxodo del campo. Durante la década del sesenta, la emigración fue una característica en las tres regiones estudiadas, en donde la mujer ocupaba un lugar preponderante en la economía familiar y era la que, de acuerdo con la visión del Estado, podía evitar los desplazamientos.

Pese a su rol en la familia y su acción en el desarrollo económico de estos ciclos productivos, los datos estatales la invisibilizaron como rabajadora rural. Para contrarrestar este vacío en las fuentes, la autora se vale de fotografías y de la historia oral. En los relatos se visibiliza el trabajo de la mujer en el hogar y en el campo. Estas memorias del pasado rural argentino nos permiten aproximarnos al proceso del éxodo del campo a la ciudad, logrando entender las realidades cambiantes que tuvo el mundo agrario en los treinta años analizados.

Además, De Arce destaca la participación de las mujeres en las corporaciones agrarias,estudiando la Sociedad Rural Argentina(SRA) y la Asociación

${ }^{1}$ Universidad Nacional del Nordeste. Contacto: almiron.historia@gmail.com 
de Cooperativas Argentinas(ACA) y recalcando en cada corporación cuál fue su disímiles discursos y representaciones respecto al lugar ocupado por la mujer. Permite, así, reflexionar sobre cómo las mujeres construyeron, durante la última parte del siglo $\mathrm{XX}$, lugares de representación en distintas instituciones rurales, con el objetivo de afian- zar y mejorar sus condiciones de vida. Consecuentemente, el aporte de la obra para los estudios agrarios es fundamental y se convierte en una lectura obligatoria para avanzar en investigaciones con perspectiva de género y reconstruir las memorias de los actores rurales, en especial, en las regiones marginales como el NEA y el NOA. 